\title{
Curriculum research for students with intellectual disabilities: a content-analytic review
}

\author{
Gøril Moljord \\ Department of Special Needs Education, University of Oslo, Norway \\ Correspondence
}

Gøril Moljord goril.moljord@ isp.uio.no

Gøril Moljord is currently a PhD candidate at the Department of Special Needs Education, University of Oslo. Her academic interests are aims in education and curriculum, intellectual disability, ethics and the philosophy of (special) education. 


\section{Curriculum research for students with intellectual disabilities: a content-analytic review}

Curriculum content, the issue of what to teach is fundamental. For students with intellectual disabilities (ID), the choice of educational content is crucial in a life span perspective. Curriculum research for this learner group is sparse. Drawing on a curriculum approach, the purpose of the current review is to analyse trends in curricular research, and discuss implications for further curricular research and policy. Curricular research articles from 1994-2016 were identified from databases, using systematic search procedures and specific criteria for inclusion. A content-analytic review using deductive and inductive approaches was conducted to categorise the literature. Based on prior review studies, functional life skills and cognitive academic content formed the analytical fulcrum. The results showed that cognitive academic articles had the highest coverage in the literature. Further, that cognitive academic articles showed a steep increase in publication frequency in contrast to functional life skill articles. If curricular research on functional life skills stagnates, curriculum policy and practice may fail to provide students with ID the skills necessary for social and practical adaption in their communities. A discursive connection to normative curricular frameworks is essential to analyse and guide curricular choices. This article provides analytical insight and directions for future research in the field of curriculum research for students with ID.

Key words: intellectual disability, curriculum, review, functional life skills, access, inclusion 


\section{Introduction}

At its best, education equips students with knowledge and skills that allow them to define and pursue their own goals, and prepares them for participation in the life of their communities (Phillips and Siegel 2015). Consequently, curriculum content, the issue of what to teach to students in all levels of education is a fundamental issue (ibid). The conceptualisation of curriculum varies in different traditions. However, in its simplest form, curriculum can be viewed as the course of study (Jung and Pinar 2016, 29). This study is based on the assumption that the constitution of subject matter in curriculum is normative and prescriptive, insofar as educational efforts are meant to shape individuals (Deng and Luke 2008, 67). Both in theory and practice, curriculum entails the normative selection and classification of knowledge from the archive of human knowledge (ibid). A relative absence of attention to knowledge or curricular content is noted from the field of curriculum studies. This is seen in relation to the remarkable rise of a learning discourse and preoccupation with competencies and academic standards (Deng 2015, 723). For students with ID, the choice of curriculum content is crucial to meeting their educational needs and interests in a life span perspective. Curricular research and policy guide practice. In turn, the curriculum received affects post-school success and outcomes such as employment and independent living (Bouck 2010; Alwell and Cobb 2009).

Inclusive education has been globally endorsed as a political objective stemming from the World Conference on Special Needs Education in Salamanca in 1994 (Reindal 2016, 1). The Salamanca Statement clearly reflects the idea of overcoming the divide between regular and special education (ibid; Kiuppis 2014, 753), but the application of the inclusion ideology in the classroom is portrayed as a continuing challenge (Ferguson 2008). Regarding students with ID, there is mounting tension between curricular content 
from a typical academic general curriculum versus that of functional life skills (Ayres et al. 2011, Shurr and Bouck 2013, Alwell and Cobb 2009). While the whole research field of special needs education is at times defined in terms of inclusion (Nilholm and Göransson 2017, 1), little research has been conducted on curriculum access and curriculum content offered to students with ID (Ware 2014; Shurr and Bouck 2013). In general, curriculum research in this field is sparse, and is reported to be declining (Shurr and Bouck 2013, Nietupski et al. 1997). What research continuously shows is that people with ID experience, for various reasons, marginalisation and limited opportunities for self-determination and participation both in and out of school (Verdonschot et al. 2009, Garrels 2016, Wendelborg and Tøssebro 2010, Sagen and Ytterhus 2014). According to Sen (1992), 'the equality of what' is essential to questions about justice. It is therefore imperative to investigate what course of study the curriculum takes for this learner group. The purpose of this study is to analyse trends in international curricular research regarding students with ID, and discuss the implications for further research and policy. That is, analyse 'the what' and the value of this.

The research question guiding the study was: What characterises content in curricular research for students with ID? To inquire into this, curricular research literature from 1994-2016 was identified from electronic research databases and analysed in a content-analytic review utilising a curriculum theoretical framework. A research discourse, as a written interchange of ideas (Merriam Webster 2017), has a potential to analyse, criticise and develop research, policy and practice. The identified literature is treated as a research discourse of curricular ideas regarding education for students with ID, a discourse this study aims to participate in and extend. In order to bring the research frontier forward, literature reviews should not only be generative, i.e. 
built on the scholarship of others (Boote and Beile 2006); it should also search relevant work outside the defined field found to have important implications for the study (Maxwell 2006). This study continues from earlier curriculum research review studies by Nietupski et al. (1997) and Shurr and Bouck (2013). However, while the prior studies focused on moderate and severe ID, this study addresses any 'level' of ID. This study bases its understanding of ID on the conceptualisations from the American Association on Intellectual and Developmental Disabilities (AAIDD 2010). Just as in the most recent version of DSM, AAIDD have abandoned severity levels of ID based on IQ scores (APA 2016). With the aspiration to situate and extend the issue of curriculum content for students with ID in a broader field of curriculum theory and policy discourse, the curriculum theoretical approach and systematic search procedures in this study aim to form the analytic and methodological innovations in this field. A curriculum theoretical approach is suggested as a promising departure from which to analyse curriculum for this student population.

\section{Curriculum inquiry}

John Goodlad and associates (1979) identified key distinctions in how curricula materialises as both intention and reality. Five dimensions of curriculum were identified; the ideological, the formal, the perceived, the operational and the experienced (Goodlad 1979, 60-63). Limiting the term curriculum to the plans made for teaching is not satisfactory because plans can be ignored or modified (Glatthorn et al. 2012 ,4). There is not always concurrence between the curricular policy documents and what actually happens in the classroom. The actualised curriculum, as perceived and carried out by educators, experienced by students and/or observed by a third party (ibid, 5), is also essential in curriculum thinking. Goodlad's conceptualisation can function as 
an analytic structure to compare curriculum inquiries towards curricular policy (the formal curriculum), how teachers interpret and carry out the curriculum (the perceived and operational curriculum), and how students experience the classroom (the experienced curriculum). What becomes evident is that clarification of what dimension of curriculum inquiry one engages in would benefit cumulative research. As this study's focus is on trends and ideas in curriculum research, this is considered to adhere to the study of the ideal curriculum; 'construed by scholars and teachers to reflect funded knowledge' (Glatthorn et al. 2012, 6). In Goodlad's terms, the words 'ideological' and 'ideational' are equally suitable, and are used synonymously to refer to the ideas behind the curriculum. Any curriculum, whether ideal or representative of sociopolitical compromises, reflects ideologies (Goodlad 1979, 59). The ideological curricula can be identified by examining textbooks and teachers' guides for the underlying ideas (ibid, 60). In this study, a systematically identified sample of curricular research literature adheres to this collection of written material which is interpreted for ideas.

\section{Students with intellectual disabilities and the curriculum}

A curriculum can be viewed as the education system's attempt to reach a match between the students' abilities and needs, and the needs of society, thereby fulfilling the aims of education (Kelly 2009, cited in Ware 2014, 491). Similarly, pedagogy operates in the middle ground between the child and the curriculum (Biesta 2014, 31). Knowledge about the characteristics, abilities and interests of students with ID is therefore pivotal in curriculum theory and practice. The AAIDD characterises ID as significant limitations both in intellectual and adaptive functioning, and onset before the age of 18 (AAIDD 2010,1). Intelligence is viewed as a general mental ability, comprising the ability to reason, solve problems, think abstractly, learn quickly, 
comprehend complex ideas and learn from experience (ibid,31). Due to limitations in these areas, many children with ID experience difficulties in cognitive and academic achievement (ibid,196). Adaptive behaviour is defined as the practical, social and conceptual skills that have been learned and are performed by people in their everyday lives (ibid, 43). AAIDD put equal emphasis on intellectual and adaptive functioning, with the latter being perceived as relative to the current environmental demands. This means that a person's overall functioning may vary and improve over time given proper support (AAIDD 2010, Parmenter et al. 2007). An understanding of adaptive behaviour is critical to educators because of its role in understanding the phenomenon of ID and providing a framework for person-referenced education goals, and focusing on an essential dimension of human functioning (Tasse et al. 2012, 291). In this article, it is argued that both curriculum theory and practice for this student population ought to address the developmental potential in both the intellectual and the adaptive domain as associated with ID. Deciding what to teach needs to be consistent with what the student needs to learn. Considering practical and social skills, we shall see that the concept of adaptive behaviour relates to a functional life skills approach to curriculum.

\section{Shifting trends and legislation framing curricular research}

Ideological zeitgeists influence trends in curriculum policy, research and practice. Prior to the nineteenth century, people with ID were seen as uneducable (Wehmeyer and Lee 2007, 560). The shifting ideas framing educational provision for this learner group have been described, in theory, as a progression from segregation, via integration and mainstreaming to inclusion (ibid, pp.561-562). According to Dymond and Orelove (2001, 110), a developmental approach to curriculum dominated the beginning of the 1970s. This was followed by a functional approach from the mid-1970s, which aimed to 
develop the social and practical life skills necessary for participation and adult independent living (Dymond and Orelove 2001, Parmenter et al. 2007). In the 1980s, Dymond and Orelove (2001) identified an ecological approach, followed by a trend towards inclusive education in the 1990s. Although highly endorsed, no common interpretation of inclusion has been widely adopted (Nilholm and Göransson 2017; Wehmeyer and Lee 2007, 563). School policy legislation both in the USA and Britain now both stress progress in, or access to the general education curriculum for students eligible for special education (Ware 2014, 492; Ayres et al. 2011,12; Shurr and Bouck $2013,83)$. Since the introduction of this legislation, it has been debated whether one common curriculum really is appropriate for all students (ibid). Dymond and Orelove (2001) pinpoint central ideas in curricular approaches based on selected publications. However, as this present study aims to characterise what appears to be the general trend of ideas in an international curricular research discourse, inferences from a broader set of systematic identified research publications are conducted.

\section{Research on curriculum content for students with ID -- prior and present study}

The research question guiding this present review study was: What characterises content in curricular research for students with ID? The study builds on important findings and recommendations from earlier curriculum research review studies by Nietupski et al. (1997) and Shurr and Bouck (2013). Shurr and Bouck (2013) conducted manual searches of ten selected journals within the field, six of which were similar to the journals reviewed in the study by Nietupski et al. (1997). Nietupski et al. (1997) reviewed articles from 1976-1995 and Shurr and Bouck's study (2013) from 1996-2010. What was included as curricular articles in these studies may have been made clearer, but a focus on target population and enhancement of skills was stated. A US school- 
based context was indicated in Shurr and Bouck's (2013) study, while the catchment of the study by Nietupski et al. (1997) did not seem apparent. In both the earlier studies, the curricular articles were categorised systematically by curricular focus (cognitiveacademic, functional life skills, sensorimotor, interaction, communication, other, and in Shurr and Bouck's study also mixed), research methodology and publication frequency. Shurr and Bouck's (2013) study also categorised the articles by educational setting. The authors note that they struggled with this categorisation, due to the mixed, unspecified or lack of description of context in the articles reviewed. This point is important. Firstly, Shurr and Bouck $(2013,82)$ stated that articles with an unspecified or mixed context represented $81 \%$ of the articles included in their review. This may lead to a potential risk of this review including articles that do not relate to a school context, and thereby not taking part in a curriculum discourse. Secondly, lack of context description compromises research replication. Thirdly, lack of clarity of the context and applicability of the study creates difficulties in actual use of the research results in appropriate settings (Shurr and Bouck 2013). They suggest that future research should address this issue and provide precise descriptions of the curricular context in focus (85). The inclusion criteria and the context for gathering, analysing and drawing conclusions from data in this present study are described in detail in the method section.

Both Nietupski et al. $(1997,53)$ and Shurr and Bouck $(2013,83)$ report an overall low and declining number of curricular articles throughout the review spans. A prominent finding in Shurr and Bouck's study (ibid) is that within the limited curricular literature, focus on cognitive academic content had a significant increase over the review span to rival functional life skills as the most common focus of curricular research from 2006-2010. They suggest that based on the emerging data trend, cognitive academic-related articles may surpass functional life skills as the most researched 
curricular content in the future (84). They discuss several explanations for this, one of them being a shift of focus from curricular content specific to students with ID to an emphasis on the adoption of and access to the general education curriculum (ibid, 83). Furthermore, Shurr and Bouck (2013) suggest that an increased legislative emphasis on access to general education curricular content could explain the overall decrease in curriculum research for this student population.

These earlier review studies offer important findings in curricular research for students with ID. However, due to their limited focus on moderate and severe ID, this study does not aim to make direct comparisons. Findings are not differentiated by level of ID in this study because when reviewing the literature different practises and noncoherence in reporting or restricting the findings to a particular 'level' were found. In addition, 'level' appears as a contested concept also theoretically by somehow varying cut-off scores between 'levels'. To reflect current thinking, the 'level' of ID is viewed as functioning relative to the environmental demands, of which the curriculum is one. Nevertheless, due to the choices of delineations and recommendations from the previous studies, this present study extends knowledge on this matter in several ways. Firstly, this study takes a curriculum theoretical approach to the content-analytic review of curricular research. A theoretical foundation is therefore used to explicate the criteria for what is included as a curricular article. Secondly, as the earlier review studies are allocated to pre-selected journals, the question of whether the results are generalizable is open. Thirdly, in contrast to the earlier reviews, systematic literature searches in international research databases were conducted in this study. Fourthly, this study investigates only one of the categories in the earlier studies - the 'curricular focus', referred to as curricular content here. The reason for this is that the issue of curriculum 
content needs to be analysed in depth within a broader curriculum theory and policy discourse.

\section{Method}

Systematic literature searches and qualitative content analysis were applied as methods. The validity of this study needs to be assessed in relation to its purpose - to provide a reliable interpretative curricular analysis of research trends - rather than perceiving validity as a context-independent property of methods or conclusions (Maxwell 2005, 105). Content analysis is described as a method for making replicable and valid inferences from text to the context of their use (Krippendorf 2004). Systematics and explication of the coding procedures and analyses are strived for in order to enhance the validity and reliability of this content-analysis study (ibid, 18). The decisions taken during the research process are made as transparent as possible. In systematic searches in international research databases, any internationally published article that matched the search terms was considered to have an equal chance of being included in this review, regardless of journal affiliation. This was considered to minimise selection bias. The particular sample of curricular articles forms the dataset from which this author draws theoretical inferences. As texts are thought to have meanings relative to particular contexts, the analyst contributes to what counts as content. Consequently, a content analysis is theory-driven in nature (ibid, 21-24). However, this does not mean that 'anything goes'. In order to enhance reliability, the researcher must explicate the context that guides their inferences (ibid). As mentioned above, the context and application of this study's analysis is a curriculum research and policy framework.

\section{Searching, inclusion and exclusion of articles}

An important task was to determine what was to be considered data - i.e. texts subject 
to further analysis. The literature search terms were selected and refined in relation to terminology in the field, as well as reviews of preliminary results lists. The searches were developed and finalised as printed reference lists with assistance from a specialised librarian. The databases used for systematic literature searches were ERIC, PsycInfo and Web of Science, all found to be relevant for educational research. These nine search terms were used and combined: A) intellectual disab*OR mental retard* AND B) curricul*OR didactic* OR educat*planning OR instruct*planning OR educat*content OR instruct*content OR educat*aim in heading, keywords and/or abstracts. In addition, searches using the databases' own subject headings 'intellectual disability’ AND ‘curriculum’ OR ‘individualised education programmes’ were conducted and combined with the keywords. The search was limited to i) peer reviewed journal articles, because of interest in focus on research (i.e. not book reviews and editorials), ii) studies published between 1994 and 2016, due to the assumption that the year 1994 represented a benchmark as a result of the Salamanca Statement. The search terms A) mental retardation (MR) and intellectual disability (ID) were chosen because these are the terms in use by the ICD-10 and AAIDD manuals, and for the somewhat clear diagnostic demarcation to non-MR/ID. Related terms such as 'cognitive impairment' and 'learning disability' were not used due to the variability of applications of these terms. The search terms $\mathbf{B}$ ) were meant to generate articles focusing on curriculum, also using related terms to capture relevant articles, but not using this exact term. Search terms such as 'education' or 'special needs education' were found to be too generic, and generated an abundance of references beyond the scope of this study to investigate. The literature search was completed on 11 August 2016.

The reference lists from the three databases were combined, and duplicates were removed electronically in EndNote and manually with help from a research assistant. 
Preliminary reviews of the references was conducted to refine and ascertain analytic categories and the inclusion criteria. The headings, keywords and abstracts in the reference list were screened. Articles included as curricular articles in this study met the following criteria as the articles addressed: a) at least one individual or a population with any level of ID/MR articulated by these precise terms irrespective of aetiology - as the main target group, and b) curriculum; i.e. curriculum theory, content, development, evaluation, and/or aim, or c) educational planning (including individual education planning), and/or enhancing skills in a school context. There were no pre-determined exclusion criteria in this study, because openness to what could be perceived as a curricular article proved to be expedient when going through the literature. However, any article that did not meet the criteria for a curricular article was excluded from further review. This was the case with the majority of the articles in the initial reference list. Most of these articles were excluded due to a research focus mainly targeting the support system or parents. Articles that clearly stated a focus outside a school context were also excluded, for example habilitation and leisure activity sites or adult education provided by institutions other than a school. The school context criteria in this study were found to be crucial to the study's aim to highlight a curricular research discourse. This means that when no context was specified for the study or a clear relation or recommendation regarding schooling or curriculum was mentioned by the author, articles were excluded from further analysis. This was the case for many articles focusing solely on the effects of instructional techniques or therapeutic (medical, psychiatric) interventions. In addition, articles that solely gave descriptions of test outcomes and validation studies of assessment tools were excluded when the authors did not relate or discuss implications for educational planning. Thus, these kinds of articles were not considered to be particularly connected to a curriculum discourse. 


\section{Analytical coding of articles}

The 256 included articles were retrieved as printed full texts, reviewed and categorised in four categories, two of which were obtained deductively and two inductively during this review. The deductive categories were retained from Shurr and Bouck $(2013,79)$ and Nietupski et al. (1997, 38-39), namely category $\mathbf{1}$. FLS - functional life skills and category 2. CA - cognitive-academic. The reason for replicating these categories in this study was because they were reported to have the largest overall representation in the earlier review studies and the most clear-cut delineation to other categories, and because the relationship between CA and FLS is of special interest in this study. Articles coded as FLS were articles that addressed the variety of skills that are frequently demanded in the natural domestic, vocational and community environment, with content focusing on self-help, healthcare and leisure skills (Brown et al., as cited in Shurr and Bouck 2013, 79), as well as instructional techniques/interventions that were reported as enhancing such skills. Furthermore, studies were included in the FLS category when the author referred to the skills as functional or when the studies focused on behavioural, communication, social and intrapersonal skills (for example self-determination) - all found to be relevant for cross context daily living. Articles regarding sex education were also included in this category. The articles coded as CA were articles that addressed cognitive skills and/or traditional academic subjects, such as mathematics, science, reading, writing, spelling and pre-academic tasks (Nietupski et al.1997), and also instructional techniques/interventions that were reported as enhancing such skills. Also included in this category were articles whose primary focus was on enhancing access to and the adoption of the general education curriculum. 
During the review process, it became apparent that many of the included articles did not match the FLS or CA category. Two analytic categories were then inductively applied: category 3. C - curriculum, and 4. CA/FLS - cognitive academics and functional life skills. These categories were not based on the earlier review studies. Rather, these categories emerged from interpretations of this study's specific dataset and were termed by this author. Articles coded as $\mathbf{C}$ focused on various analyses of curriculum, involving discussions of curriculum models, design, evaluation and/or principles for planning (i.e. IEP and transition planning) for the target population. Articles addressing critical analyses of access to and adoption of the general education curriculum were also coded as $\mathbf{C}$. The $\mathrm{C}$ category was found to be relevant to apply in order to identify more theoretically focused curriculum research. As a functional and a cognitive academic approach to curriculum need not be mutually exclusive, a combination category of these two topics was also applied. Articles coded as CA/FLS equally addressed a combination of FLS and CA content. One example is a study of interventions with the self-determined learning model of instruction on access to the general curriculum (Shogren et al. 2012). Each article was reviewed and matched with the category descriptions. The code representing one of the four categories of curricular foci was manually recorded beside each reference. The code applied was based on the authors of the articles' own statement of the aim and/or main focus in their articles, mainly stated in the heading and abstract. A second review was conducted to re-affirm the coding.

Despite a low publication frequency, curricular articles related to sensorimotor, physical activities and communication were found, and could have been coded separately. However, they all also related to, and were coded under FLS in this review. Applying a generic category termed other was considered to be too vague. The category 
descriptions underwent slight changes during the coding process in order to obtain a match between a coded reference and the code description. Memos were recorded during the coding process to capture immediate reflections of the literature..A research assistant converted the coded data material to an Excel protocol where each reference was numbered and arranged by their code and year of publication. This format enabled the publication frequency to be recorded for the review span in each category.

\section{Results}

The search generated 219 references in ERIC, 413 in PsycInfo and 1011 in Web of Science (WoS). The reference list from WoS was reduced to 739 after exclusion of articles from journals of obvious irrelevance. When the reference lists from the three databases were combined and duplicates removed, the data material consisted of $\mathbf{1 1 1 8}$ articles. After inclusion/exclusion, 256 articles were defined as curricular articles, thus representing the curriculum discourse regarding students with ID in the period 19942016. Analytical coding of articles showed:

- 105 cognitive-academic articles

- 82 functional life skills articles

- 58 curriculum articles

- 11 combination of cognitive-academic and functional life skills articles

Articles focusing on cognitive-academic content had the highest overall coverage, followed by the articles focusing on functional life skills content. Articles focusing on various analyses of curriculum and curriculum planning were the third most researched content. The least covered topic was the combination of cognitive-academic and functional life skills content, which did not appear before 2002. From 1994 to 2005, the number of publications in the CA and FLS category did not differ much. From 2006, the 
publication frequency of the two categories begins to diverge, with the number of CA articles published exceeding the number of FLS articles throughout the rest of the review span. Both FLS articles and CA articles showed an increase in publication frequency. However, the CA category showed in the period 2006-2016 almost a three doubling of publications -77- compared with publications in the period 1994-2005 which was 28 . In contrast, the publications in the he FLS category did not even double, with the corresponding figures 32 and 50, respectively. In the period 2012-2016, the publication of FLS articles seem to decline. However, this is a short time span and this needs to be investigated further to see if this is a trend.

Consequently, what seems to characterise content in curricular research for students with ID from 1994 to 2016 is a cognitive-academic approach. This finding supports the hypothesis suggested by Shurr and Bouck (2013), that cognitive-academic may surpass functional life skills as the most researched curricular content in the future. However, this is perhaps to be expected when the entire range of ID is included in this current review, instead of only moderate and severe ID as in the previous reviews. So direct comparisons with previous reviews are of limited applicability here, because the literature sample is different. A record of publication frequency in all categories in this study showed that curricular research for students with ID appears to increase within the review span. This finding appears to be contrary to earlier review studies which finds curricular research to decline (Shurr and Bouck 2013, Nietupski et al. 1997).

This article provides only an overview of trends in curricular research. In-depth analysis within each category of included literature is beyond the scope of this study. However, some characteristics of the literature are noted here. In several C-A articles, teaching literacy, numeracy and science concepts to students with ID was common. Curricular policy documents and/or jurisdiction were commonly reported as background 
for, or justification of these contents. In the FLS category, research related to selfdetermination was the most common content. Articles related to sensorimotor, physical activities and communication represented the least covered topic within this category. In the CA category, content focusing on transition and individual educational planning was common. Although not dominating, Bouck et al. (see reference list) appear to be significant contributors to curriculum analyses and development in this category, with a focus on functional curriculum in particular. The combination category CA/FLS was not extensive, but could be perceived as an evolving blended curriculum field. Particularly noteworthy from reviewing the $\mathrm{C}$ category is that although a share of the articles had a critical-analytic position, connections to conceptual, theoretical and/or normative frameworks to analyse and guide curriculum thinking and theory were sparse.

\section{Discussion and implications for curriculum research and policy}

The results of the study must be interpreted within its context of limitations. Two issues of the validity of this study are raised. Firstly, the coding of the included articles was conducted by this author alone, which represents a significant limitation of the study. However, as mentioned above, to strengthen the validity and reliability, the searching and coding procedures and the inferences drawn from data are made as transparent as possible. This study adheres to the AAIDD definition and the ICD-10/DSM naming of the ID condition. Due to ID or MR being strict inclusion criteria, many curricular research articles were excluded from this review. This could also represent a limitation of the study, since important literature may have been omitted. The author acknowledges that curriculum research addressing this student population using terms widely used in the UK, such as 'learning disabilities', may obviously be of relevance for the field. A different set of inclusion criteria might have given a different literature 
sample. Nevertheless, in order to unify and extend the curricular discourse, distinct terminology and clarification of inquiry are essential in order to communicate research findings consistently across fields.

This study reports that cognitive-academic-related articles had the highest overall coverage in the literature, a category in rapid increase. On this basis, it is suggested that the curricular research discourse for students with ID from the period 1994-2016 appears to be characterised by a cognitive-academic approach. In line with Shurr and Bouck $(2013,83)$, one possible explanation for this could be a saturation in the FLS research field. However, as educational opportunities for students with ID improve over time due to shifting societal and technological conditions, this is not a likely explanation (ibid). Instead, more FLS research is needed for updated knowledge on what skills are functional to possess in domestic, vocational and community life in the twenty-first century. A more plausible explanation appears to be the overall influence of the ideology of inclusion and access to the general curriculum, which implicitly may shape research interest (ibid). Moreover, given research institutions' frequent need for external funding, funding agencies may also align with this political zeitgeist and finance CA-related research projects that focus on all students reaching the standards of the general academic curriculum. If the latter is considered to be 'inclusion', the appropriateness of inclusion as a research paradigm seriously needs to be questioned. Given that the whole research field of special needs education is at times defined in terms of inclusion (Nilholm and Göransson 2017, 1), it is crucial to investigate how inclusion 'materializes as both intention and reality'. Dymond and Orelove (2001) note that: 'there are some instances where inclusion appears to have become the curriculum'. Furthermore, that students with severe disabilities 'participate in the same activities as their peers without disabilities, regardless of whether the 
curriculum enables them to achieve competence in a variety of academic and functional skills areas' (110). Although the concept of inclusive education reflects the best intentions, mainstreaming creates dilemmas about what curricular content to teach. Questioning the ideology of inclusion should not be treated like a reactionary issue. Rather, it should be treated like a curricular issue, at its heart always considering the students' educational needs and interests over ideology.

Although FLS- content seems less common than CA content in curricular discourse, habilitation or occupational therapy research discourses may focus on FLScontent. Nevertheless, it is argued here that FLS should be an important part of curricular research discourse. FLS represents valuable content in the school curriculum for this group of students. As Goodlad's conceptualisations of curriculum inquiry point to, shifting trends and legislation impact curriculum design and educational practice. If we regard the individual education plan (IEP) as a hybrid between the formal and perceived curriculum, a recent Portuguese study is interesting in this context. SanchesFerreira (et al. 2013) investigated the content of 2497 IEP goals for students from age 818. It was found that IEP goals in highly individualised curricula did not appropriately focus on functional life skills content (ibid, 519). This may suggest a risk of an IEP adopting goals from a standard-based academic curriculum, thereby annexing meaningful individualised curriculum goals that may be directly tied to increased independence in identified current and future environments (Ayres et al. 2011, 12).

The current study inquires into the curriculum of ideas in research. The link between research and practice, academic debate and day-to-day life in the classroom seems to be tenuous at best (Ware 2014, 501). This leaves the question of whether FLS is becoming a less focused content in special education practice open for further research. More empirical data is needed here. Nevertheless, it is important to emphasise 
that if curricular research and policy regarding FLS stagnates, FLS may also be a less focused content in the operational and experienced curriculum for this learner group. This would compromise what there is generally diagnostic consensus about: that people with ID have limitations in adaptive behaviour, which implies the need for students with ID to learn practical and social skills for adaptive functioning in their communities. In turn, this corresponds to the school's responsibility to teach such skills. It is well documented that many students with ID do not learn life skills on their own (Cronin 1996, 53). Moreover, limitations of basic life skills together with environmental barriers may limit the quality of life of this population (Parmenter et al. 2007, 720). Development of functional life skills therefore requires systematic instruction and need to be a focused content throughout the students' school careers (Parmenter et al. 200, 693; Cronin 1996, 53). To inquire into the match between the curriculum and the student, both empirical and theoretical research along Goodlad's dimensions of curriculum are essential. For example, the experienced curriculum - students' own narratives and assessments of individual skills after schooling - can be compared to post-school outcomes (i.e. studies by Bouck et al). Although perhaps at odds with current educational policy on access to the general curriculum, it is argued here that more research on functional curriculum models is needed to prevent the risk of functional life skills becoming the 'ignored curriculum' for students with ID.

Being literate and numerate may be perceived as functional life skills of the twenty-first century. However, for a proportion of the ID-student population, the aim of being literate and numerate may be out of reach. For some students with ID focusing on sensorimotor stimulating and communication are essential. The wording of functional life skills invokes a quintessential curricular question: functional where and to whom? A functional life skills approach and a standard academic approach to teaching are not 
mutually exclusive in curriculum design. However, designing an IEP requires weighing potential benefits from developing academic competencies against the potential benefits that may follow from teaching functional life skills (AAIDD 2010, 197), thus a deliberate balance between approaches. Knowledge about curriculum design for students with ID should therefore be an essential part of the special educator's competence. The cognitive variability of students with ID requires not only methodological considerations, i.e. how to master the goals in mainstream curriculum; it also requires epistemological and ethical considerations on what kinds of knowledge are considered valuable, longitudinally relevant, and realistic to learn and apply - at a reasonable rate.

The issue of curricular content is not only a curricular question of what to choose, but also how to justify that choice. Consequently, curricular questions become an ethical issue. What knowledge and skills are of value for this group of learners? Decided by whom? Who and what does the formal curriculum value? Although several critical articles were found in this study's review, there is a gap in the literature regarding normative frameworks for developing, analysing and critiquing the curriculum for this learner group. Discussions on aims and curricular content in special education are needed, leaving the present void to the issue of what works. As Biesta (2009) reminds us, there is a need to reconnect with the question of the purpose of education. Reindal (2010) invites us to discuss the purpose of inclusion in special education. To start with purpose would link the issues of what (content) and why (aim) in education closely together. It is vital that curriculum thinking and development regarding students with ID connect to discourses on ethics, philosophy and curriculum policy in general. A truly inclusive school for all students should provide the best available knowledge on how to meet all of the students' needs and educational interests. 


\section{Acknowledgements}

I would especially like to thank Professor Solveig M. Reindal, Associate Professor Kari-Anne Bottegaard Næss and Professor Sven Nilsen for discussing ideas, and for valuable comments on earlier drafts of this article. In addition, the comments from the journal's anonymous reviewers are greatly appreciated. 


\section{References}

AAIDD, 2010. Intellectual disability. Definition, Classification, and Systems of Supports. The 11th edition of the AAIDD definition manual. USA: American Association on Intellectual and Developmental Disabilities.

APA, American Psychological Association. Defining Intellectual disability: Finally we all agree... almost. Defining and determining intellectual disability. Collected 04.10.2017 http://www.apa.org/pi/disability/resources/publications/newsletter/2016/09/intellectualdisability.aspx

Alwell, M.,Cobb, B. 2009."Functional Life Skills Curricular Interventions for Youth with Disabilities. A Systematic Review". Career Development for Exceptional Individuals, 32:2, 89-93.doi: $10.1177 / 0885728809336656$

Ayres, K. M., Douglas, K. H, Lowrey, K. A, Sievers, C. 2011. "I Can Identify Saturn but I Can't Brush My Teeth: What Happens when the Curricular Focus for Students with Severe Disabilities Shifts." Education and Training in Autism and Developmental Disabilities 46 (1):11-21.

Biesta, G. 2009. "Good Education in an Age of Measurement: On the Need to Reconnect with the Question of Purpose in Education." Educational Assessment, Evaluation and Accountability 21 (1):33-46. DOI: 10.1007/s11092-008-9064-9

Biesta, G. 2014. "Pragmatising the curriculum: bringing knowledge back into the curriculum conversation, but via pragmatism. The Curriculum Journal, 25:1, 29-49. http://dx.doi.org/10.1080/09585176.2013.874954

Boote, D.N., Beile, P. 2006. "On "Literature Reviews of, and for, Educational Research": A Response to the Critique by Joseph Maxwell." Educational Researcher 35 (9):32-35. http://www.jstor.org/stable/4124801

Bouck, E. 2010. «Reports of life skills training for students with intellectual disabilities in and out of school." Journal of Intellectual Disability Research 54 (12) 1093-1103. DOI: 10.1111/j.1365-2788.2010.01339

Cronin, M.E. 1996. "Life Skills Curricula for Students with Learning Disabilities: A review of the Literature." Journal of Learning Disabilities 29 (1):53-68. DOI: $10.1177 / 002221949602900108$

Deng, Z. \& Luke, A. 2008. "Subject matter: defining and theorizing school subjects." In F. M. Connelly, M. F. He \& J. Phillion The SAGE handbook of curriculum and instruction (pp.66-88). Thousand Oaks, CA: SAGE Publications Ltd. doi: 10.4135/9781412976572.n4

Deng, Z. 2015. «Michael Young, knowledge and curriculum: an international dialogue." Journal of Curriculum Studies, 47:6, 723-732. http://dx.doi.org/10.1080/00220272.2015.1101492

Dymond, S. K., Orelove, F. P. 2001. "What Constitutes Effective Curricula for Students with Severe Disabilities?" Exceptionality 9 (3):109-22. http://dx.doi.org/10.1207/S15327035EX0903_2

Ferguson, D. 2008. "International trends in inclusive education: the continuing challenge to teach each and every one." European Journal of Special Needs Education, vol.23, 2008, issue 2. http://dx.doi.org/10.1080/08856250801946236

Garrels, V. 2016. "Goal setting and planning for Norwegian students with and without intellectual disabilities: Wishing upon a star?" European Journal of Special Needs Education:1-15. doi: 10.1080/08856257.2016.1261487.

Glatthorn, A.A., F. Boschee, B.M. Whitehead, B.F. Boschee. 2012. " Curriculum Leadership: Strategies for Development and Implementation." Third edition ed. USA: SAGE Publications Inc.

Goodlad, J. 1979. "Curriculum Inquiry. The Study of Curriculum Practice." McGraw-Hill Book Company. 
Jung, J.-H. J. \& Pinar, W. F. (2016). "Conceptions of curriculum" . In D.Wyse L. Hayward \& J. Pandya The SAGE Handbook of curriculum, Pedagogy and Assessment (Vol. 2, pp.2946). 55 City Road, London: SAGE Publications Ltd. doi: 10.4135/9781473921405.n2

Kiuppis, F.2014. "Why (not) associate the principle of inclusion with disability? Tracing connections from the start of the `Salamanca Process`". International Journal of Inclusive Education, 18:7, 746-761. DOI: 10.1080/13603116.2013.826289

Krippendorff, K. 2004. «Content Analysis. An Introduction to its Methodology". Second edition ed. USA: SAGE Publications.

Maxwell, J. A. 2006. "Literature Reviews of, and for, Educational Research: A Commentary on Boote and Beile's "Scholars before Researchers." Educational Researcher 35 (9):2831. http://www.jstor.org/stable/4124800

Maxwell, J. A. 2005. «Qualitative research design. An interactive Approach." Second Edition. SAGE Publications.

Merriam Webster. Merriam-Webster.com., n.d. Web. 26 May 2017.

Nietupski, J. , Hamre-Nietupski, S., Curtin, S., Shrikanth, K. 1997. "A Review of Curricular Research in Severe Disabilities from 1976 to 1995 in Six Selected Journals." Journal of Special Education 31 (1):36-55.

Nilholm, C., and K. Göransson. 2017. "What is meant by inclusion? An analysis of European and North American journal articles with high impact." European Journal of Special Needs Education:1-15. doi: 10.1080/08856257.2017.1295638.

Parmenter, T.R., A.D. Harman, M. Yazbeck, and V.C. Riches. 2007. "Life skills training for adolescents with intellectual disabilities." In The Handbook of Intellectual Disability and Clinical Psychology Practice, edited by A. Carr, G. O’Reilly, P. Noonan Walsh and J. McEvoy, 687-728. USA and Canada: Routledge.

Phillips, D.C., Siegel, H. "Philosophy of Education", The Stanford Encyclopedia of Philosophy (Winter 2015 Edition), Edward N. Zalta (ed.), URL = <https://plato.stanford.edu/archives/win2015/entries/education-philosophy/>.

Reindal, S.M. 2016. "Discussing Inclusive Education: An Inquiry into Different Interpretations and a Search for Ethical Aspects of Inclusion Using the Capabilities Approach." European Journal of Special Needs Education v31 (n1):p1-12 doi: http://dx.doi.org/10.1080/08856257.2015.1087123

Reindal, S.M. 2010. "What Is the Purpose? Reflections on Inclusion and Special Education from a Capability Perspective." European Journal of Special Needs Education 25 (1):1-12. http://dx.doi.org/10.1080/08856250903450806

Sagen, L. M. , Ytterhus B. 2014. "Self-Determination of Pupils with Intellectual Disabilities in Norwegian Secondary School." European Journal of Special Needs Education 29 (3):344-357. http://dx.doi.org/10.1080/08856257.2014.909174

Sanches-Ferreira, M, Lopes-dos-Santos, Pedro, Alves, S., Santos, M. Silveira-Maia, M. 2013. "How Individualised Are the Individualised Education Programmes (IEPs): An Analysis of the Contents and Quality of the IEPs Goals." European Journal of Special Needs Education 28 (4):507-520. http://dx.doi.org/10.1080/08856257.2013.830435

Sen, A. 1992 Inequality reexamined. New York: Russell Sage Foundation.Harvard University Press.

Shogren, K. A., Palmer S., Wehmeyer M., Williams, D.K, Little T.D. 2012. "Effect of Intervention with the Self-Determined Learning Model of Instruction on Access and Goal Attainment." Remedial and Special Education 33 (5):320-330. $10.1177 / 0741932511410072$

Shurr, J. , Bouck E. 2013. "Research on Curriculum for Students with Moderate and Severe Intellectual Disability: A Systematic Review." Education and Training in Autism and Developmental Disabilities 48 (1):76-87.

Tasse, M. J., Robert L. Schalock, Giulia Balboni, Hank Bersani, Jr., Sharon A. BorthwickDuffy, Scott Spreat, David Thissen, Keith F. Widaman, and Dalun Zhang. 2012. "The Construct of Adaptive Behavior: Its Conceptualization, Measurement, and Use in the 
Field of Intellectual Disability." American Journal on Intellectual and Developmental Disabilities 117 (4):291-303. https://doi.org/10.1352/1944-7558-117.4.291

Verdonschot, M. M. L., L. P. de Witte, E. Reichrath, W. H. E. Buntinx, L. M. G. Curfs. 2009. "Community Participation of People with an Intellectual Disability: A Review of Empirical Findings." Journal of Intellectual Disability Research 53 (4):303-318. 10.1111/j.1365-2788.2008.01144.x

Ware, J. 2014. "Curriculum considerations in meeting the educational needs of learners with severe intellectual disabilities." In L. Florian The SAGE Handbook of special education (Vol. 2, pp.491-503). 55 City Road, London: SAGE Publications Ltd. doi: 10.4135/9781446282236.n31

Wehmeyer, M.L., S-E Lee. 2007. "Educating children with intellectual disability and autismspectrum disorders." In The Handbook of intellectual disability and Clinical Psychology Practice, edited by A. Carr, G. O`Reilly, P. Walsh and J. McEvoy, 559-605. USA and Canada: Routledge.

Wendelborg, C. Tøssebro, J. 2010. "Marginalisation Processes in Inclusive Education in Norway: A Longitudinal Study of Classroom Participation." Disability and Society 25 (6):701-714. http://dx.doi.org/10.1080/09687599.2010.505744 


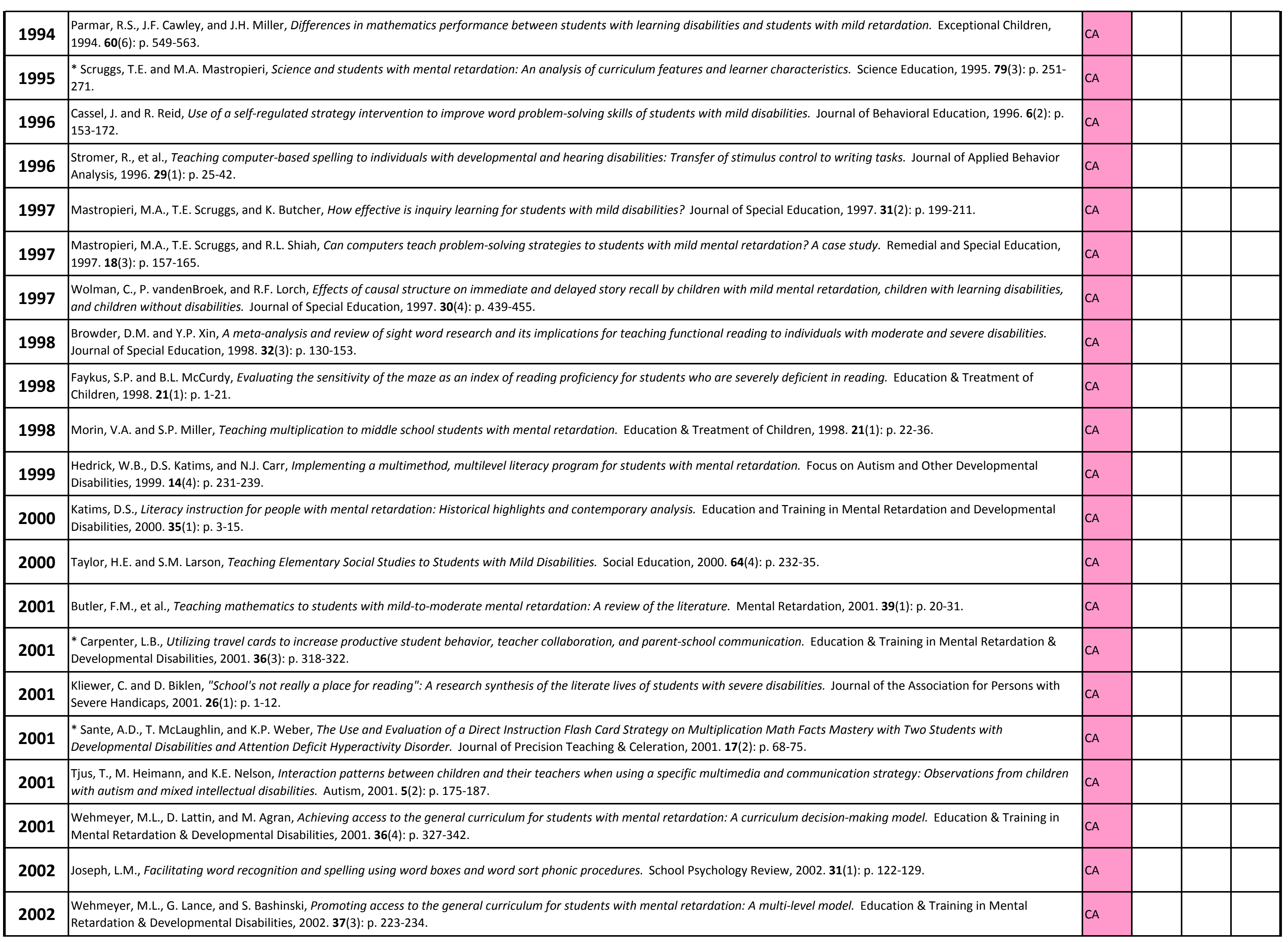




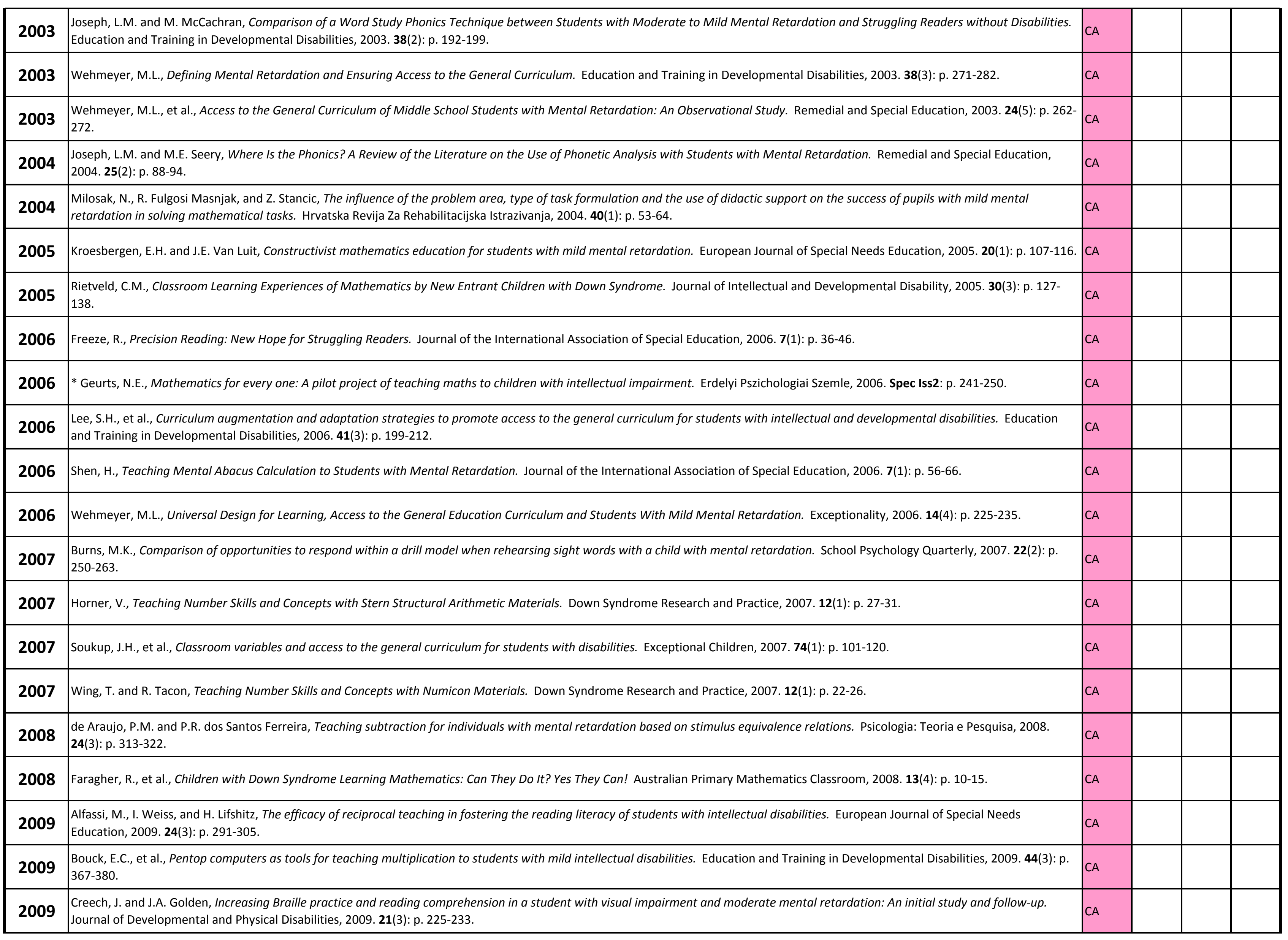


2009 Jimenez, B.A., D.M. Browder, and G.R. Courtade, An Exploratory Study of Self-Directed Science Concept Learning by Students With Moderate Intellectual Disabilities. Research and Practice for Persons with Severe Disabilities, 2009. 34(2): p. 33-46.

2009

ee, E. and S. Lee, Effects of instructional rubrics on class engagement behaviors and the achievement of lesson objectives by students with mild mental retardation and their typical peers. Education and Training in Developmental Disabilities, 2009. 44(3): p. 396-408. Education, 2009. 43(1): p. 29-44.

2010

Alberto, P.A., R.E. Waugh, and L.D. Fredrick, Teaching the reading of connected text through sight-word instruction to students with moderate intellectual disabilities. Research in Developmental Disabilities, 2010. 31(6): p. 1467-1474.

2010

lor, J.H., et al., Methods for increasing the intensity of reading instruction for students with intellectual disabilities. Education and Training in Autism and Developmental Disabilities, 2010. 45(4): p. 500-511.

2010

Allor, J.H., et al., Individualized Research-Based Reading Instruction for Students with Intellectual Disabilities: Success Stories. TEACHING Exceptional Children, 2010. 42(3): p. 6-12

2010

Allor, J.H., et al., Teaching students with moderate intellectual disabilities to read: An experimental examination of a comprehensive reading intervention. Education and Training in Autism and Developmental Disabilities, 2010. 45(1): p. 3-22.

2010

列 Developmental Disabilities, 2010. 45(3): p. 378-399.

Erickson, KA, P. Hatch, and S. Clindon, Literach, Assit

2010

scobal, G., R.A.S. Rossit, and C. Goyos, Number concept acquisition by people with intellectual disabilities. Psicologia em Estudo, 2010. 15(3): p. 467-475.

2010

2010

2010

2010

2010

letcher, D. R.T. Boon, and D.F. Cihak, Effects of the TOUCHMATH program compared to a number line strategy to teach addition facts to middle school students with moderate intellectud disabilities. Education and Training in Autism and Developmental Disabilities, 2010. 45(3): p. 449-458.

Idol, L., Reading success: Validation of a specialized literacy program (1978-2007). Remedial and Special Education, 2010. 31(2): p. 97-115.

Reis, M.G.A.D., et al., Using Information Technology Based Exercises in Primary Mathematics Teaching of Children with Cerebral Palsy and Mental Retardation: A Case Study. Turkish Online Journal of Educational Technology TOJET, 2010. 9(3): p. 106-118.

Scruggs, T.E., et al., Mnemonic Strategies: Evidence-Based Practice and Practice-Based Evidence. Intervention in School and Clinic, 2010. 46(2): p. 79-86.

Zisimopoulos, D.A., Enhancing multiplication performance in students with moderate intellectual disabilities using pegword mnemonics paired with a picture fading technique. Journal of Eehavioral Education, 2010. 19(2): p. 117-133.

2011 evelopmental Disabilities, 2011. 46(3): p. 315-325. Monari Martinez, E. and N. Benedetti, Learning Mathematics in Mainstream Secondary Schools: Experiences of Students with Down's Syndrome. European Journal of Special Needs Education, 2011. 26(4): p. 531-540.

2011 Sahin, Y.G. and F.M. Cimen, AN INTERACTIVE ATTENTION BOARD: IMPROVING THE ATTENTION OF INDIVIDUALS WITH AUTISM AND MENTAL RETARDATION. Turkish Online Journal of Educational Technology, 2011. 10(1): p. 24-35.

2012

A. Childre, Increasing literacy skills for students with intellectual and developmental disabilities: Effects of integrating comprehensive reading instruction with sign language. Education and Training in Autism and Developmental Disabilities, 2012. 47(4): p. 487-501. Browder, D.M., B.A. Jimenez, and K. Trela, Grade-aligned math instruction for secondary students with moderate intellectual disability. Education and Training in Autism and Developmental Disabilities, 2012. 47(3): p. 373-388.

2012 * Hord, C. and E.C. Bouck, Review of academic mathematics instruction for students with mild intellectual disability. Education and Training in Autism and Developmental Disabilities, 2012. $47(3):$ p. 389-400.

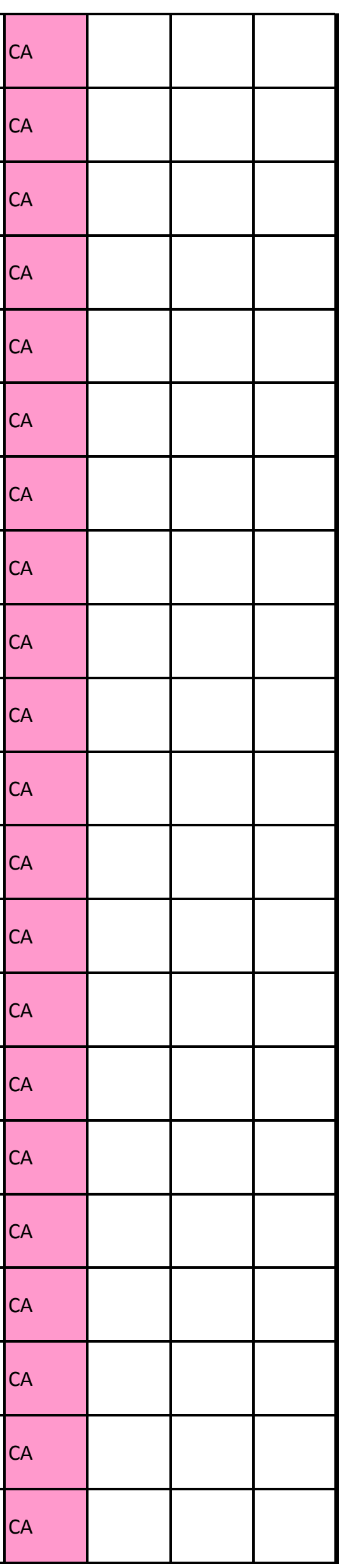




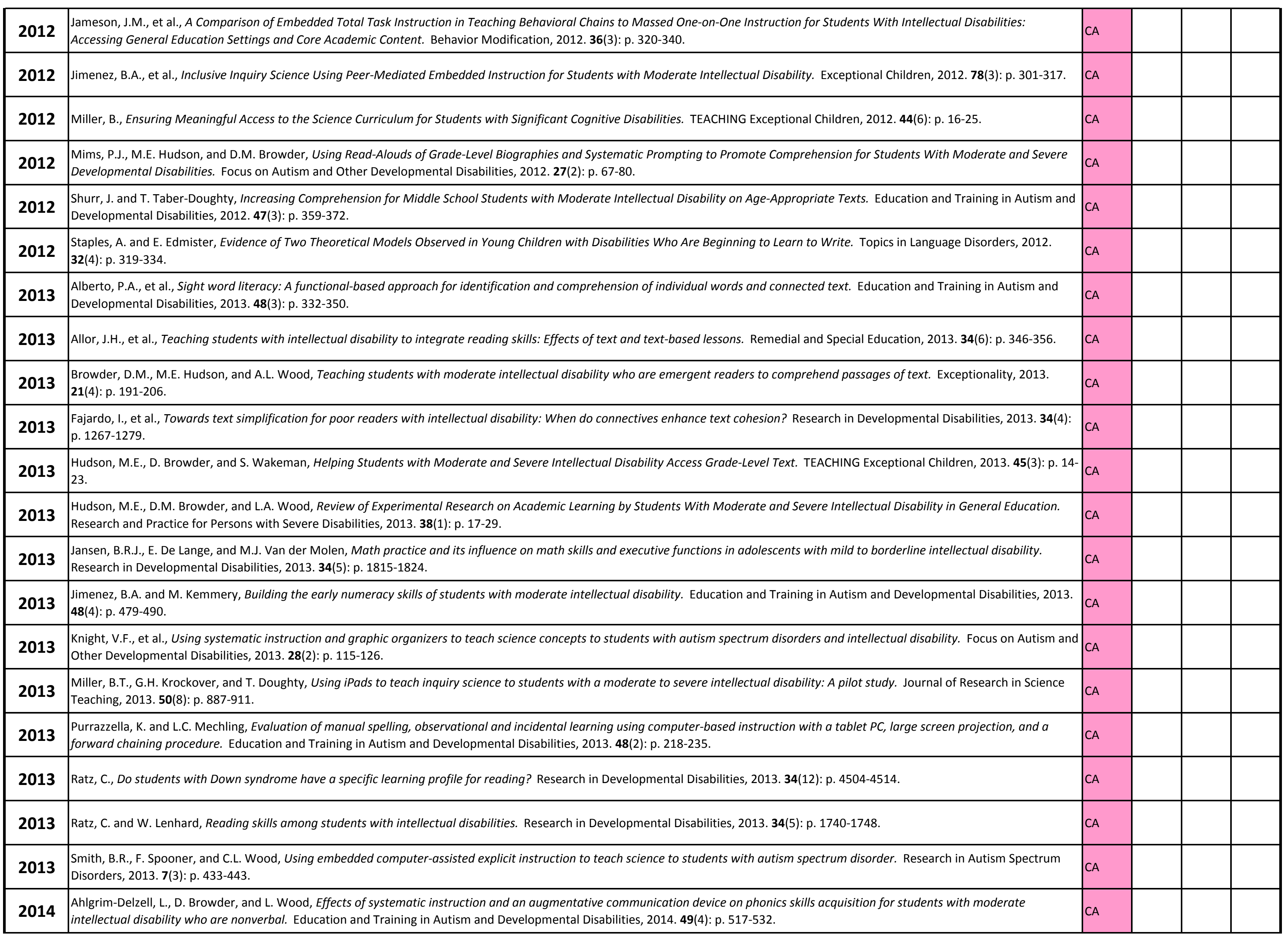


2014 Celik, S. and S. Vuran, Comparison of Direct Instruction and Simultaneous Prompting Procedure on Teaching Concepts to Individuals with Intellectual Disability. Education and Training in Autism and Developmental Disabilities, 2014. 49(1): p. 127-144.

2014

Deganay Bilgi, A and E R. Ormen, The Impact of Modified Multi-component Cognitive Strategy Instruction in the Acquisition of Metacognitive Strategy Knowledge in the Text Comprehension Process of Students with Mental Retardation. Kuram Ve Uygulamada Egitim Bilimleri, 2014. 14(2): p. 707-714. Hudson, M.E., D.M. Browder, and B.A. Jimenez, Effects of a peer-delivered system of least prompts intervention and adapted science read-alouds on listening comprehension for participants with moderate intellectual disability. Education and Training in Autism and Developmental Disabilities, 2014. 49(1): p. 60-77.

2014 Jimenez, B.A., Y.Y. Lo, and A.F. Saunders, The Additive Effects of Scripted Lessons Plus Guided Notes on Science Quiz Scores of Students With Intellectual Disability and Autism. Journal of Special Education, 2014. 47(4): p. 231-244.

2014

S iff K. and R. T. Boon, Effects of computer-based graphic organizers to solve one-step word problems for middle school students with mild intellectual disability: A preliminary study. Research in Developmental Disabilities, 2014. 35(8): p. 1828-1837.

2014 Tzanakaki, P., et al., An individualized numeracy curriculum for children with intellectual disabilities: A single blind pilot randomized controlled trial. Journal of Developmental and Physical Disabilities, 2014. 26(5): p. 615-632.

2014

Yakubova, G. and E.C. Bouck, Not all created equally: Exploring calculator use by students with mild intellectual disability. Education and Training in Autism and Developmental Disabilities, 2014. 49(1): p. 111-126.

2015

m-Delzell L and C. Rivera, A content comparison of literacy lessons from 2004 to 2010 for students with moderate and severe intellectual disability. Exceptionality, 2015. 23(4): p. 258-269.

Cakir, O., E. Teker, and E.C. Aybek, The Effect of Adaptive Learning Environment in Teaching the Number Concept to Students with Intellectual Disabilities. Croatian Journal of EducationHrvatski Casopis Za Odgoj I Obrazovanje, 2015. 17: p. 199-221.

2015

Della-Malone, H.I., M. Konrad, and R.C. Pennington, ACCESS! Teaching Writing Skills to Students with Intellectual Disability. TEACHING Exceptional Children, 2015. 47(5): p. 272-280.

2015

* Hicks, S., C.J. Rivera, and C.L. Wood, Using direct instruction: Teaching preposition use to students with intellectual disability. Language, Speech, and Hearing Services in Schools, 2015. 46(3): p. 194-206.

2015

Hord, C. and Y.P. Xin, Teaching area and volume to students with mild intellectual disability. The Journal of Special Education, 2015. 49(2): p. 118-128.

2015

$Y$ et al. Effects of the TIP strategy on problem solving skills of young adults with intellectual disability. Education and Training in Autism and Developmental Disabilities, 2015. 50(1): p. 31-42.

amgochian, E.M. and L.R. Ketterlin-Geller, The 2\% Transition: Supporting Access to State Assessments for Students with Disabilities. TEACHING Exceptional Children, 2015. 48(1): p. 28-35. Jimenez, B.A. and K. Staples, Access to the Common Core state standards in mathematics through early numeracy skill building for students with significant intellectual disability. Education and Training in Autism and Developmental Disabilities, 2015. 50(1): p. 17-30.

2015 C. and A. Cavkaytar, SCIENCE EDUCATION FOR STUDENTS WITH INTELLECTUAL DISABILITY: A CASE STUDY. Journal of Baltic Science Education, 2015. 14(6): p. 804-820. Wood, L., D.M. Browder, and L. Flynn, Teaching Students with Intellectual Disability to Use a Self-Questioning Strategy to Comprehend Social Studies Text for an Inclusive Setting. Research and Practice for Persons with Severe Disabilities, 2015. 40(4): p. 275-293.

2016 Ainsworth, M.K., et al., Teaching phonics to groups of middle school students with autism, intellectual disabilities and complex communication needs. Research in Developmental Disabilities, 2016. 56: p. 165-176.

2016 Goransson, K., T. Helliblom

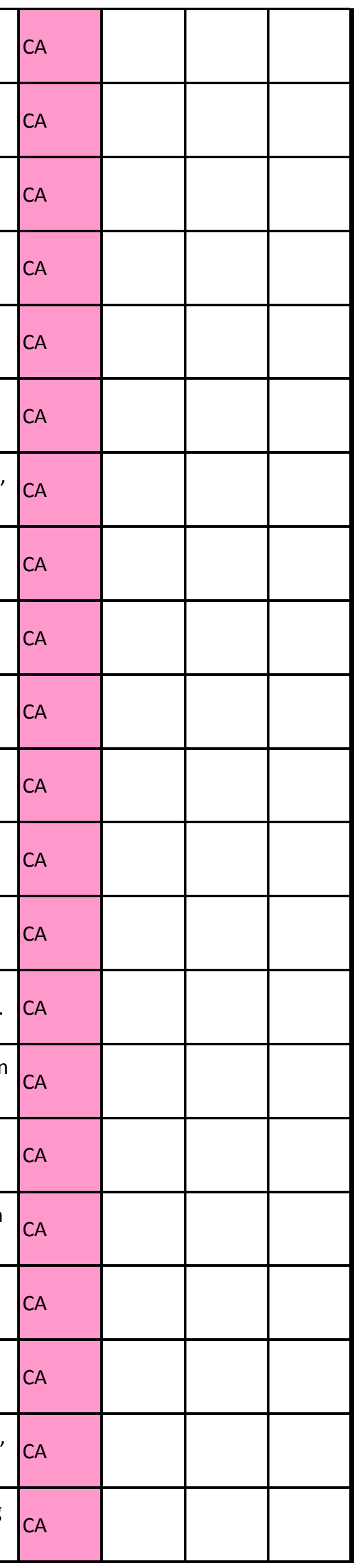




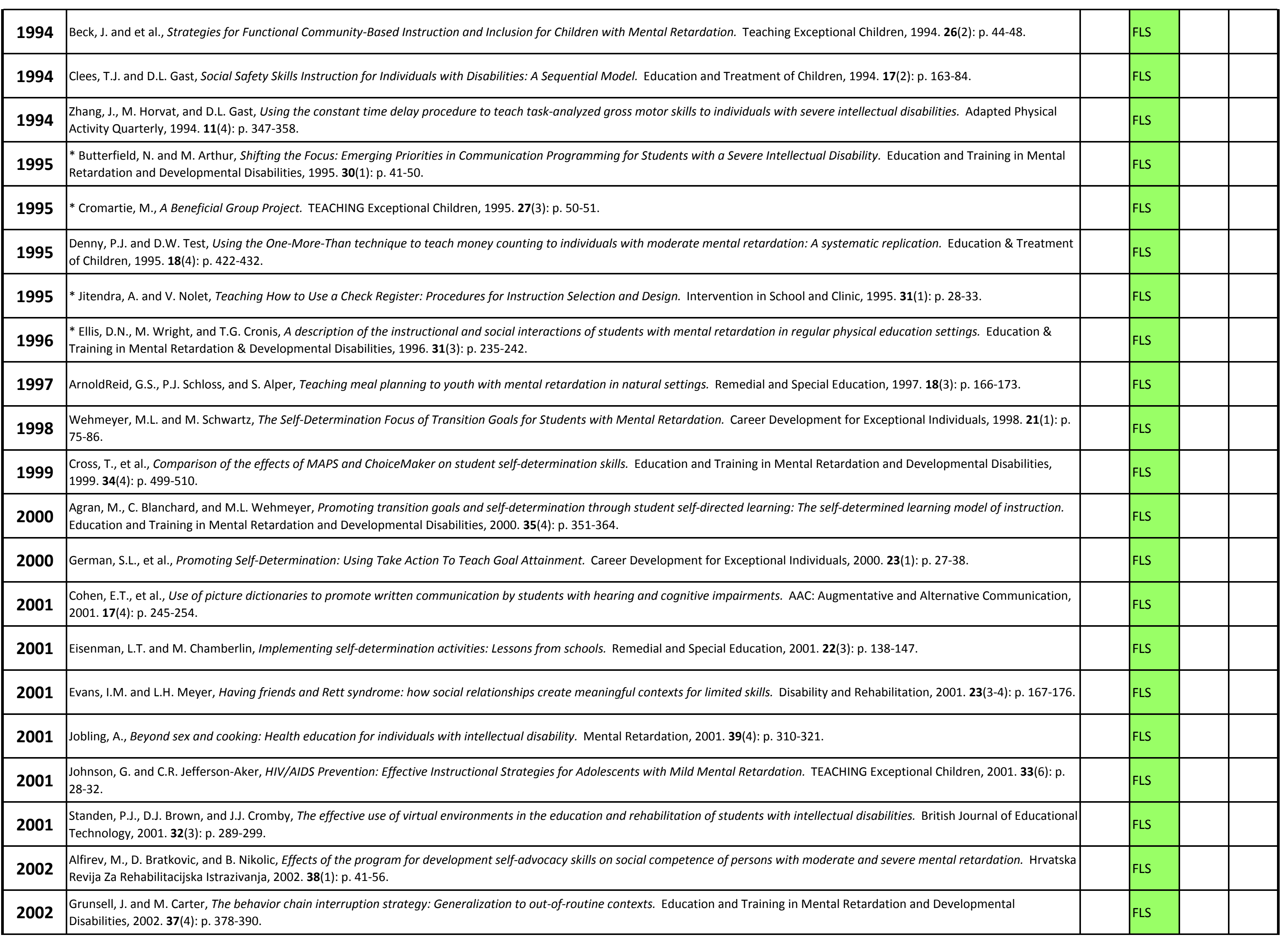




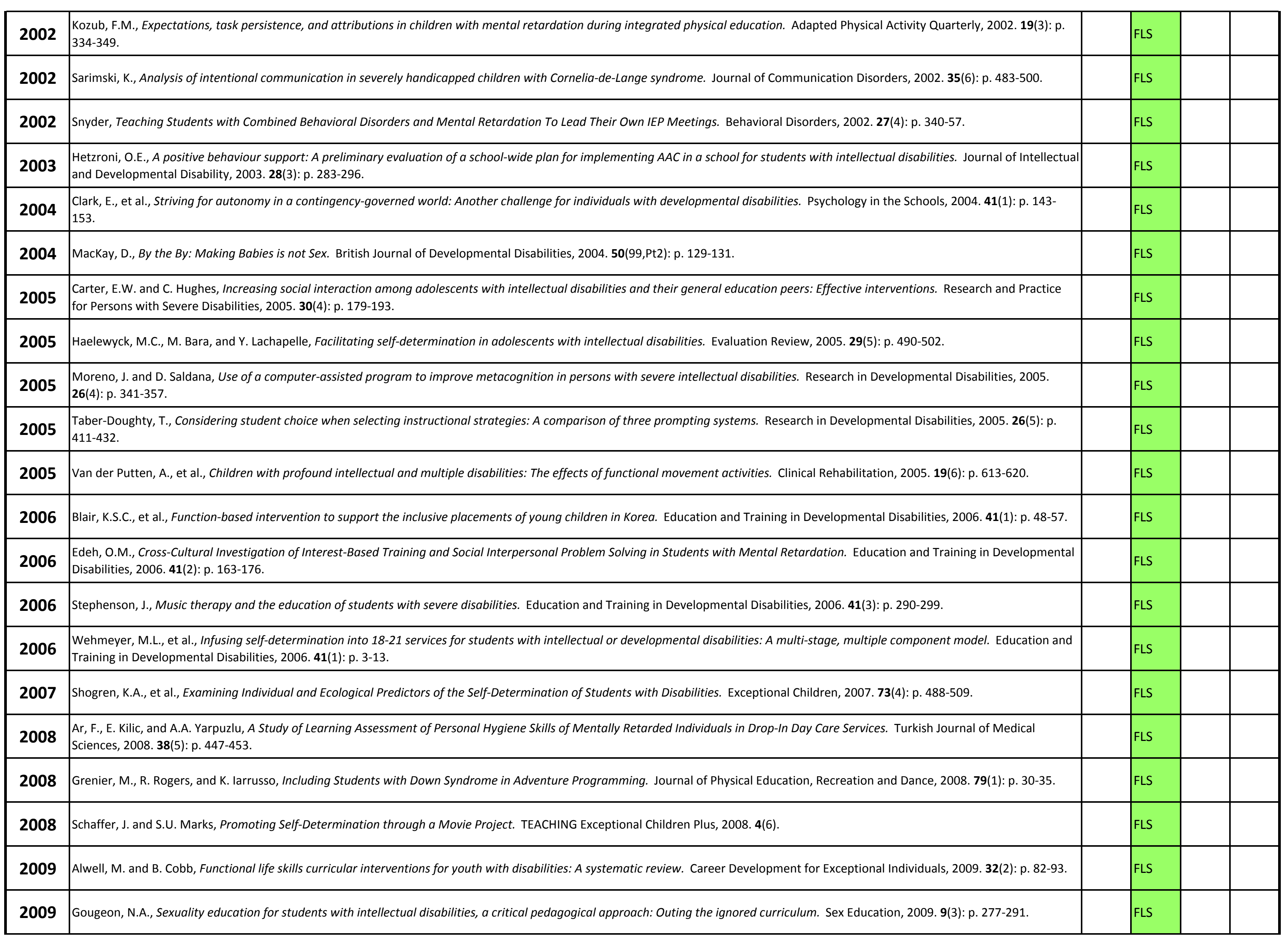


2009

2009

2010

2010

2011

2011

2011

2011

2011

2011

2012

2012

2012

2012

2012

2012

2012

2012

2012

2013

2013

Lofgren-Mayenrtenson, L., The Invisibility of Young Homosexual Women and Men with Intellectual Disabilities. Sexuality and Disability, 2009. 27(1): p. 21-26.

列 Exceptionality, 2009. 17(2): p. 103-116.

Watanbe, A., Implementation of courses on distribution and service in special support high schools for students with intellectual disabilities. Japanese Journal of Special Education, 2009. 7(1): p. 23-35.

Borisov, C. and G. Reid, Students with intellectual disabilities acting as tutors: An interpretative phenomenological analysis. European Journal of Special Needs Education, 2010. 25(3): $\mathrm{p}$. 295-309.

Bouck, E., Reports of life skills training for students with intellectual disabilities in and out of school. Journal of Intellectual Disability Research, 2010. 54(12): p. 1093-1103.

Douglas, K.H., et al., The Effectiveness of Electronic Text and Pictorial Graphic Organizers to Improve Comprehension Related to Functional Skills. Journal of Special Education Technology, 2011. 26(1): p. 43-56.

shizu, N. and S. Isawa, Effects of social skills training as career education at a special school for students with mental retardation or autism. Japanese Journal of Special Education, 2011. 49(2): p. 203-213.

( N. M. Kempen, and A. Ruscheinski, Differentiated pedagogy as inclusive practice: The "Learn not to Burn" curriculum for learners with severe intellectual disabilities. Education as Change, 2011. 15(2): p. 191-208.

Pei, H. and M. Watanabe, Teaching choice-making skills to students with moderate mental retardation in a school setting in China. Japanese Journal of Special Education, 2011. 49(1): p. 85

Young, H., et al., Multi-sensory storytelling as an aid to assisting people with profound intellectual disabilities to cope with sensitive issues: A multiple research methods analysis of engagement and outcomes. European Journal of Special Needs Education, 2011. 26(2): p. 127-142.

Zisimopoulos, D., J. Sigafoos, and G. Koutromanos, Using Video Prompting and Constant Time Delay to Teach an Internet Search Basic Skill to Students with Intellectual Disabilities. Education and Training in Autism and Developmental Disabilities, 2011. 46(2): p. 238-250.

Agran, M., et al., Asking Students About the Importance of Safety Skills Instruction: A Preliminary Analysis of What They Think Is Important. Research and Practice for Persons with Severe Disabilities, 2012. 37(1): p. 45-52.

Bouck, E.C., et al., Promoting Independence through Assistive Technology: Evaluating Audio Recorders to Support Grocery Shopping. Education and Training in Autism and Developmental Disabilities, 2012. 47(4): p. 462-473.

Cannella-Malone, H.I., et al., Comparing the Effects of Video Prompting with and without Error Correction on Skill Acquisition for Students with Intellectual Disability. Education and Trainin in Autism and Developmental Disabilities, 2012. 47(3): p. 332-344.

Coughlin, J., et al., Effects of a Self-Monitoring Strategy on Independent Work Behavior of Students with Mild Intellectual Disability. Education and Training in Autism and Developmental Disabilities, 2012. 47(2): p. 154-164.

Gomez-Vela, M., et al., Assessment of the Self-Determination of Spanish Students with Intellectual Disabilities and other Educational Needs. Education and Training in Autism and Developmental Disabilities, 2012. 47(1): p. 48-57.

Lofgren-Martenson, L., "I want to do it right!" A pilot study of Swedish sex education and young people with intellectual disabilities. Sexuality and Disability, 2012. 30(2): p. $209-225$.

van Bysterveldt, A.K., et al., Personal Narrative Skills of School-Aged Children with Down Syndrome. International Journal of Language and Communication Disorders, 2012. 47(1): p. 95105.

Washington, B.H., C. Hughes, and J.C. Cosgriff, High-poverty youth: Self-determination and involvement in educational planning. Career Development for Exceptional Individuals, 2012. 35(1): p. 14-28.

Aderemi, T.J. and B.J. Pillay, Sexual abstinence and HIV knowledge in school-going adolescents with intellectual disabilities and non-disabled adolescents in Nigeria. Journal of Child and Adolescent Mental Health, 2013. 25(2): p. 161-174.

Avcioglu, H., Effectiveness of Video Modelling in Training Students with Intellectual Disabilities to Greet People When They Meet. Kuram Ve Uygulamada Egitim Bilimleri, 2013. 13(1): p. 466 477.

\begin{tabular}{|l|l|l|l|}
\hline & FLS & & \\
\hline & FLS & & \\
\hline & FLS & & \\
\hline & FLS & & \\
\hline & FLS & & \\
\hline & FLS & & \\
\hline & FLS & & \\
\hline & FLS & & \\
\hline & FLS & & \\
\hline & FLS & & \\
\hline & FLS & & \\
\hline & FLS & & \\
\hline & FLS & & \\
\hline & FLS & & \\
\hline
\end{tabular}




\begin{tabular}{|c|c|c|c|}
\hline 2013 & $\begin{array}{l}\text { Cease-Cook, J., D.W. Test, and L.S. Scroggins, Effects of the CD-Rom Version of the 'Self-Advocacy Strategy' on Quality of Contributions in IEP Meetings of High School Students with } \\
\text { Intellectual Disability. Education and Training in Autism and Developmental Disabilities, 2013. 48(2): p. 258-268. }\end{array}$ & FLS & \\
\hline 2013 & $\begin{array}{l}\text { Haveman, M., et al., Mobility and public transport use abilities of children and young adults with intellectual disabilities: Results from the 3-year Nordhorn Public Transportation } \\
\text { Intervention Study. Journal of Policy and Practice in Intellectual Disabilities, 2013. 10(4): p. 289-299. }\end{array}$ & FLS & \\
\hline 2013 & $\begin{array}{l}\text { Hughes, C., et al., Student Self-Determination: A Preliminary Investigation of the Role of Participation in Inclusive Settings. Education and Training in Autism and Developmental Disabilities, } \\
\text { 2013. 48(1): p. 3-17. }\end{array}$ & FLS & \\
\hline 2013 & $\begin{array}{l}\text { Kvas, S., et al., Assessing Mobility Competences of Children With Intellectual Disabilities: Development and Results of the Mobility Assessment Schedule. Journal of Policy and Practice in } \\
\text { Intellectual Disabilities, 2013. 10(4): p. 300-306. }\end{array}$ & FLS & \\
\hline 2014 & Barnard-Brak, L., et al., Predictors of access to sex education for children with intellectual disabilities in public schools. Intellectual and Developmental Disabilities, 2014. 52(2): p. 85-97. & FLS & \\
\hline 2014 & $\begin{array}{l}\text { Brunosson, A., et al., To use a recipe-Not a piece of cake. Students with mild intellectual disabilities' use of recipes in home economics. International Journal of Consumer Studies, } 2014 . \\
\text { 38(4): p. 412-418. }\end{array}$ & FLS & \\
\hline 2014 & $\begin{array}{l}\text { Carrington, S., et al., Promoting self-determination for better health and wellbeing for adolescents who have an intellectual disability. Australasian Journal of Special Education, 2014. 38(2): } \\
\text { p. 93-114. }\end{array}$ & FLS & \\
\hline 2014 & $\begin{array}{l}\text { Liou, W.Y., An Illustrated Scale Measuring the SexualaEuroAbuse Prevention Knowledge of Female High School Students with Intellectual Disabilities in Taiwan. Sexuality and Disability, } \\
\text { 2014. 32(2): p. 135-151. }\end{array}$ & FLS & \\
\hline 2014 & $\begin{array}{l}\text { Miller, B. and T. Taber-Doughty, Self-monitoring checklists for inquiry problem-solving: Functional problem-solving methods for students with intellectual disability. Education and Training } \\
\text { in Autism and Developmental Disabilities, 2014. } \mathbf{4 9 ( 4 ) : ~ p . ~ 5 5 5 - 5 6 7 . ~}\end{array}$ & FLS & \\
\hline 2014 & $\begin{array}{l}\text { Sagen, L.M. and B. Ytterhus, Self-Determination of Pupils with Intellectual Disabilities in Norwegian Secondary School. European Journal of Special Needs Education, 2014. 29(3): p. 344- } \\
\text { 357. }\end{array}$ & FLS & \\
\hline 2014 & Winges-Yanez, N., Discourse Analysis of Curriculum on Sexuality Education: FLASH for Special Education. Sexuality and Disability, 2014. 32(4): p. 485-498. & FLS & \\
\hline 2015 & $\begin{array}{l}\text { Cihak, D.F., et al., Incorporating Functional Digital Literacy Skills as Part of the Curriculum for High School Students with Intellectual Disability. Education and Training in Autism and } \\
\text { Developmental Disabilities, 2015. 50(2): p. 155-171. }\end{array}$ & FLS & \\
\hline 2015 & $\begin{array}{l}\text { Finlay, W., et al., 'Understanding' as a practical issue in sexual health education for people with intellectual disabilities: A study using two qualitative methods. Health Psychology, } 2015 . \\
\text { 34(4): p. 328-338. }\end{array}$ & FLS & \\
\hline 2015 & $\begin{array}{l}\text { Mazzotti, V.L., K.R. Kelley, and C.M. Coco, Effects of Self-Directed Summary of Performance on Postsecondary Education Students' Participation in Person-Centered Planning Meetings. } \\
\text { Journal of Special Education, 2015. 48(4): p. 243-255. }\end{array}$ & FLS & \\
\hline 2015 & $\begin{array}{l}\text { Plavnick, J.B., T. Kaid, and M.C. MacFarland, Effects of a school-based social skills training program for adolescents with autism spectrum disorder and intellectual disability. Journal of } \\
\text { Autism and Developmental Disorders, 2015. 45(9): p. 2674-2690. }\end{array}$ & FLS & \\
\hline 2015 & Smith, K.A., et al., Evaluating the Effects of a Video Prompt in a System of Least Prompts Procedure. Career Development and Transition for Exceptional Individuals, 2015. 38(1): p. 39-49. & FLS & \\
\hline 2015 & $\begin{array}{l}\text { Wong, M.W.-y., Adapting the Music Curriculum for Senior Secondary Students with Intellectual Disabilities in Hong Kong: Content, Pedagogy and Mindsets. Music Education Research, } \\
\text { 2015. 17(1): p. 71-87. }\end{array}$ & FLS & \\
\hline 2016 & $\begin{array}{l}\text { Bouck, E.C., R. Satsangi, and W. Bartlett, Comparing a number line and audio prompts in supporting price comparison by students with intellectual disability. Research in Developmental } \\
\text { Disabilities, 2016. 53-54: p. 342-357. }\end{array}$ & FLS & \\
\hline 2016 & Favazza, P.C., et al., The Young Athletes Curriculum: Impact on Children with Disabilities in Kenya. Journal of Research in Childhood Education, 2016. 30(1): p. 113-127. & FLS & \\
\hline 1994 & $\begin{array}{l}\text { Foster-Johnson, L. and et al., Preferred Curricular Activities and Reduced Problem Behaviors in Students with Intellectual Disabilities. Journal of Applied Behavior Analysis, 1994. 27(3): p. } \\
\text { 493-504. }\end{array}$ & & \\
\hline 1994 & *Smith, T.E. and A. Hilton, Program design for students with mental retardation. Education \& Training in Mental Retardation \& Developmental Disabilities, 1994. 29(1): p. 3-8. & & \\
\hline
\end{tabular}




\begin{tabular}{|c|c|c|c|}
\hline 1995 & $\begin{array}{l}\text { * Dunlap, G., et al., Modifying activities to produce functional outcomes: Effects on the problem behaviors of students with disabilities. Journal of the Association for Persons with Severe } \\
\text { Handicaps, 1995. 20(4): p. 248-258. }\end{array}$ & & c \\
\hline 1995 & *Liebman, J.L. and J.F. Goodman, Learning in Early Intervention Programs: The Generalization and Maintenance of IEP Objectives. Early Education and Development, 1995. 6(2): p. 127-43. & & c \\
\hline 1995 & $\begin{array}{l}\text { *Smith, T.E. and I.K. Puccini, Position statement: Secondary curricula and policy issues for students with mental retardation. Education \& Training in Mental Retardation \& Developmental } \\
\text { Disabilities, 1995. 30(4): p. 275-282. }\end{array}$ & & c \\
\hline 1995 & $\begin{array}{l}\text { Wehmeyer, M. and M. Lawrence, Whose Future Is It Anyway? Promoting Student Involvement in Transition Planning. Career Development for Exceptional Individuals, 1995. 18(2): p. 69- } \\
\text { 83. }\end{array}$ & & C \\
\hline 1996 & $\begin{array}{l}\text { Ferro, J., L. FosterJohnson, and G. Dunlap, Relation between curricular activities and problem behaviors of students with mental retardation. American Journal on Mental Retardation, } \\
\text { 1996. 101(2): p. 184-192. }\end{array}$ & & c \\
\hline 1996 & *Rusch, F.R. and D.M. Millar, The transition to adulthood and the world of work by youth with mental retardation. Current Opinion in Psychiatry, 1996. 9(5): p. 328-331. & & c \\
\hline 1997 & $\begin{array}{l}\text { *Miner, C.A. and P.E. Bates, The effect of person centered planning activities on the IEP/transition planning process. Education \& Training in Mental Retardation \& Developmental } \\
\text { Disabilities, 1997. 32(2): p. 105-112. }\end{array}$ & & c \\
\hline 1997 & Nietupski, J., et al., A review of curricular research in severe disabilities from 1976 to 1995 in six selected journals. Journal of Special Education, 1997. 31(1): p. 36-55. & & c \\
\hline 1999 & Devlieger, P.J. and J.S. Trach, Mediation as a Transition Process: The Impact on Postschool Employment Outcomes. Exceptional Children, 1999. 65(4): p. 507-23. & & c \\
\hline 2000 & $\begin{array}{l}\text { Langone, J., C.A. Langone, and P.J. McLaughlin, Analyzing special educators' views on community-based instruction for students with mental retardation and developmental disabilities: } \\
\text { Implications for teacher education. Journal of Developmental and Physical Disabilities, 2000. 12(1): p. 17-34. }\end{array}$ & & c \\
\hline 2001 & Allen, S.K., et al., The Effects of "Self-Directed" IEP on Student Participation in IEP Meetings. Career Development for Exceptional Individuals, 2001. 24(2): p. 107-20. & & c \\
\hline 2002 & $\begin{array}{l}\text { Blanchett, W.J. and P.S. Wolfe, A review of sexuality education curricula: Meeting the sexuality education needs of individuals with moderate and severe intellectual disabilities. Research } \\
\text { and Practice for Persons with Severe Disabilities, 2002. 27(1): p. 43-57. }\end{array}$ & & c \\
\hline 2002 & Braden, J.S. and J.E. Obrzut, Williams Syndrome: Neuropsychological findings and implications for practice. Journal of Developmental and Physical Disabilities, 2002. 14(3): p. 203-213. & & c \\
\hline 2002 & Mittler, P., Educating pupils with intellectual disabilities in England: Thirty years on. International Journal of Disability, Development and Education, 2002. 49(2): p. 145-160. & & c \\
\hline 2002 & Shaddock, A.J., An Unplanned Journey into Individualised Planning. International Journal of Disability, Development and Education, 2002. 49(2): p. 191-200. & & c \\
\hline 2004 & Bouck, E.C., State of curriculum for secondary students with mild mental retardation. Education and Training in Developmental Disabilities, 2004. 39(2): p. 169-176. & & c \\
\hline 2005 & $\begin{array}{l}\text { Bouck, E.C., Impact of Factors on Curriculum and Instructional Environments for Secondary Students with Mild Mental Retardation. Education and Training in Developmental Disabilities, } \\
\text { 2005. 40(3): p. 309-319. }\end{array}$ & & c \\
\hline 2005 & al., Quality of life for people with intellectual disabilities in China: A cross-culture perspectives study. Journal of Intellectual Disability Research, 2005. 49(10): p. 745-749. & & c \\
\hline
\end{tabular}


Kiarie, M.W., Educational Services for Students with Mental Retardation in Kenya. International Journal of Special Education, 2006. 21(2): p. 47-54.

Fidler, D.J. and L. Nade, Education and children with Down syndrome: Neuroscience, development, and intervention. Mental Retardation and Developmental Disabilities Research Reviews, 2007. 13(3): p. 262-271.

T.M., M. McSheehan, and R.M. Sonnenmeier, Presumed competence reflected in the educational programs of students with IDD before and after The Beyond Access.

2007 \begin{tabular}{l|l}
$W$ \\
21
\end{tabular}

2008 21. 85-95.

Ryndak, D.L., et al., Access to the General Curriculum: The Mandate and Role of Context in Research-based Practice for Students with Extensive Support Needs. Research and Practice for Persons with Severe Disabilities, 2008. 33-34: p. 199-213.

2008

Tadema, A.C., C. Vlaskamp, and W. Ruijssenaars, Implementation of a programme for students with profound intellectual and multiple disabilities in schools: Three case studies. Education and Training in Developmental Disabilities, 2008. 43(4): p. 529-540.

2008

est, D.W., Seamless Transition for All. Research and Practice for Persons with Severe Disabilities, 2008. 33(3): p. 98-99.

Todd, S., Learning to take the world seriously: An ethnographic study of the management of knowledge in a special school for children with intellectual disabilities. Journal of Intellectual Disabilities, 2009. 13(3): p. 221-238.

P. The Content of Support of Persons with Profound Intellectual and Multiple Disabilities: An Analysis of the Number and Content of Goals in the Educational Programmes. Journal of Applied Research in Intellectual Disabilities, 2009. 22(4): p. 391-394. Developmental Disabilities, 2010. 45(4): p. 487-499.

2010

Kontu, EK and R. Pirttima, Teaching methods and curiculum models used in Finlund in the education of students diagnosed with having severe profound intellectud disabiltes. B Journal of Learning Disabilities, 2010. 38(3): p. 175-179.

Thompson, J.R., M.L. Wehmeyer, and C. Hughes, Mind the Gap! Implications of a Person-Environment Fit Model of Intellectual Disability for Students, Educators, and Schools. Exceptionality, 2010. 18(4): p. 168-181.

2011 Bouck, E.C., A snapshot of secondary education for students with mild intellectual disabilities. Education and Training in Autism and Developmental Disabilities, 2011. 46(3): p. 399-409. Grigal, M., D. Hart, and A. Migliore, Comparing the Transition Planning, Postsecondary Education, and Employment Outcomes of Students with Intellectual and Other Disabilities. Career Development for Exceptional Individuals, 2011. 34(1): p. 4-17.

2012 Bouck, E., Secondary students with moderate/severe intellectual disability: Considerations of curriculum and post-school outcomes from the National Longitudinal Transition Study-2. Journal of Intellectual Disability Research, 2012. 56(12): p. 1175-1186.

2012

ouck, E.C. and G. Joshi, Functional curriculum and students with mild intellectual disability: Exploring postschool outcomes through the NLTS2. Education and Training in Autism and Developmental Disabilities, 2012. 47(2): p. 139-153.

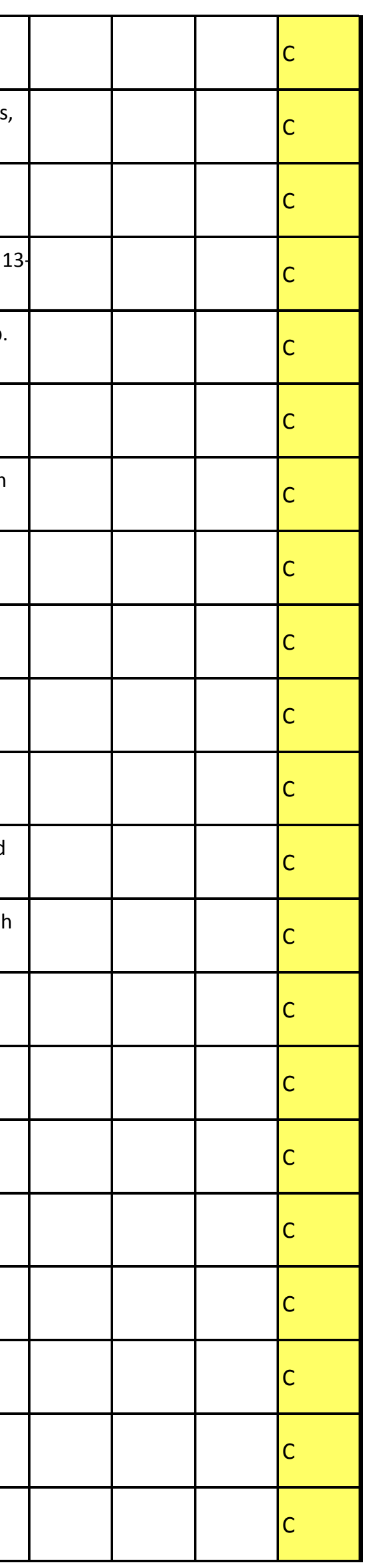




\begin{tabular}{|c|c|c|c|}
\hline 2012 & $\begin{array}{l}\text { *Noguchi, A. and H. Yoneda, Students with intellectual disabilities' access to the general curriculum: A review of standards-based reform in the United States. Japanese Journal of Special } \\
\text { Education, 2012. 49(5): p. 445-455. }\end{array}$ & & C \\
\hline 2012 & $\begin{array}{l}\text { Palmer, S.B., et al., An evaluation of the beyond high school model on the self-determination of students with intellectual disability. Career Development and Transition for Exceptional } \\
\text { Individuals, 2012. 35(2): p. } 76-84 \text {. }\end{array}$ & & C \\
\hline 2012 & $\begin{array}{l}\text { Shogren, K.A. and A.J. Plotner, Transition Planning for Students With Intellectual Disability, Autism, or Other Disabilities: Data from the National Longitudinal Transition Study-2. Intellectual } \\
\text { and Developmental Disabilities, 2012. 50(1): p. 16-30. }\end{array}$ & & C \\
\hline 2013 & $\begin{array}{l}\text { Bouck, E.C., Factors impacting receipt of a functional curriculum: A secondary analysis of the NLTS2. Education and Training in Autism and Developmental Disabilities, 2013. 48(4): p. 522- } \\
530 .\end{array}$ & & C \\
\hline 2013 & $\begin{array}{l}\text { Doyle, M.B. and M. Giangreco, Guiding Principles for Including High School Students with Intellectual Disabilities in General Education Classes. American Secondary Education, 2013. 42(1): } \\
\text { p. 57-72. }\end{array}$ & & C \\
\hline 2013 & $\begin{array}{l}\text { Shurr, J. and E.C. Bouck, Research on curriculum for students with moderate and severe intellectual disability: A systematic review. Education and Training in Autism and Developmental } \\
\text { Disabilities, 2013. 48(1): p. 76-87. }\end{array}$ & & C \\
\hline 2013 & $\begin{array}{l}\text { Trela, K. and B.A. Jimenez, From Different to Differentiated: Using 'Ecological Framework' to Support Personally Relevant Access to General Curriculum for Students with Significant } \\
\text { Intellectual Disabilities. Research and Practice for Persons with Severe Disabilities, 2013. 38(2): p. 117-119. }\end{array}$ & & C \\
\hline 2014 & $\begin{array}{l}\text { Bouck, E.C. and R. Satsangi, Evidence-base of a functional curriculum for secondary students with mild intellectual disability: A historical perspective. Education and Training in Autism and } \\
\text { Developmental Disabilities, 2014. 49(3): p. 478-486. }\end{array}$ & & C \\
\hline 2014 & $\begin{array}{l}\text { * Homma, T. and H. Yoneda, Shaping the curriculum of New York City public school "ungraded classes" (1910 1930): A historical study of the focus on social adjustment. Japanese Journal of } \\
\text { Special Education, 2014. 52(1): p. 25-38. }\end{array}$ & & C \\
\hline 2014 & $\begin{array}{l}\text { Rood, C.E., A. Kanter, and J. Causton, Presumption of Incompetence: The Systematic Assignment of Guardianship Within the Transition Process. Research and Practice for Persons with } \\
\text { Severe Disabilities, 2014. 39(4): p. 319-328. }\end{array}$ & & C \\
\hline 2014 & $\begin{array}{l}\text { *Zhang, J.-W., et al., Curriculum Adaptation in Special Schools for Students with Intellectual Disabilities (SID): A Case Study of Project Learning in One SID School in Hong Kong. Frontiers of } \\
\text { Education in China, 2014. 9(2): p. 250-273. }\end{array}$ & & C \\
\hline 2015 & $\begin{array}{l}\text { Bouck, E.C. and R. Satsangi, Is there really a difference? Distinguishing mild intellectual disability from similar disability categories. Education and Training in Autism and Developmental } \\
\text { Disabilities, 2015. 50(2): p. 186-198. }\end{array}$ & & C \\
\hline 2015 & $\begin{array}{l}\text { Stephenson, J. and M. Carter, Improving educational planning for students with severe disabilities: An evaluation of school-based professional learning. Australasian Journal of Special } \\
\text { Education, 2015. 39(1): p. 2-14. }\end{array}$ & & C \\
\hline 2015 & $\begin{array}{l}\text { Strogilos, V., E. Tragoulia, and M. Kaila, Curriculum issues and benefits in supportive co-taught classes for students with intellectual disabilities. International Journal of Developmental } \\
\text { Disabilities, 2015. 61(1): p. 32-40. }\end{array}$ & & C \\
\hline 2002 & $\begin{array}{l}\text { Agran, M., et al., Increasing the problem-solving skills of students with developmental disabilities participating in general education. Remedial and Special Education, 2002. 23(5): p. 279- } \\
288 .\end{array}$ & CAFLS & \\
\hline 2002 & $\begin{array}{l}\text { Hughes, C., et al., Using Self-Monitoring To Improve Performance in General Education High School Classes. Education and Training in Mental Retardation and Developmental Disabilities, } \\
\text { 2002. 37(3): p. 262-72. }\end{array}$ & CAFLS & \\
\hline 2004 & Crites, S.A. and C. Dunn, Teaching Social Problem Solving to Individuals with Mental Retardation. Education and Training in Developmental Disabilities, 2004. 39(4): p. $301-309$. & CAFLS & \\
\hline 2004 & Palmer, S.B., et al., Promoting Access to the General Curriculum by Teaching Self-Determination Skills. Exceptional Children, 2004. 70(4): p. 427-439. & CAFLS & \\
\hline 2006 & $\begin{array}{l}\text { Agran, M., et al., Participation of Students with Moderate to Severe Disabilities in the General Curriculum: The Effects of the Self-Determined Learning Model of Instruction. Research and } \\
\text { Practice for Persons with Severe Disabilities, 2006. 31(3): p. 230-241. }\end{array}$ & CAFLS & \\
\hline 2008 & $\begin{array}{l}\text { Cihak, D.F. and J. Grim, Teaching students with autism spectrum disorder and moderate intellectual disabilities to use counting-on strategies to enhance independent purchasing skills. } \\
\text { Research in Autism Spectrum Disorders, 2008. 2(4): p. 716-727. }\end{array}$ & CAFLS & \\
\hline
\end{tabular}


2013 Creech-Galloway, C., et al., Using a Simultaneous Prompting Procedure with an iPad to Teach the Pythagorean Theorem to Adolescents with Moderate Intellectual Disability. Research and Practice for Persons with Severe Disabilities, 2013. 38(4): p. 222-232.

2013

Karl, J., et al., Teaching Core Content Embedded in a Functional Activity to Students with Moderate Intellectual Disability Using a Simultaneous Prompting Procedure. Education and Training in Autism and Developmental Disabilities, 2013. 48(3): p. 363-378.

Roberts, C.A. and M.M. Leko, Integrating Functional and Academic Goals into Literacy Instruction for Adolescents with Significant Cognitive Disabilities through Shared Story Reading Research and Practice for Persons with Severe Disabilities, 2013. 38(3): p. 157-172.

2015 Miller, B., T. Doughty, and G. Krockover, Using science inquiry methods to promote self-detern 